\title{
Precipitation Simulations Using WRF as a Nested Regional Climate Model
}

\author{
MELISSA S. BuKOVSKY \\ School of Meteorology, University of Oklahoma, Norman, Oklahoma \\ DAVID J. KAROLY \\ School of Earth Sciences, The University of Melbourne, Melbourne, Victoria, Australia
}

(Manuscript received 20 January 2009, in final form 18 June 2009)

\begin{abstract}
This note examines the sensitivity of simulated U.S. warm-season precipitation in the Weather Research and Forecasting model (WRF), used as a nested regional climate model, to variations in model setup. Numerous options have been tested and a few of the more interesting and unexpected sensitivities are documented here. Specifically, the impacts of changes in convective and land surface parameterizations, nest feedbacks, sea surface temperature, and WRF version on mean precipitation are evaluated in 4-month-long simulations. Running the model over an entire season has brought to light some issues that are not otherwise apparent in shorter, weather forecast-type simulations, emphasizing the need for careful scrutiny of output from any model simulation. After substantial testing, a reasonable model setup was found that produced a definite improvement in the climatological characteristics of precipitation over that from the National Centers for Environmental Prediction-National Center for Atmospheric Research global reanalysis, the dataset used for WRF initial and boundary conditions in this analysis.
\end{abstract}

\section{Introduction}

Initially, the Weather Research and Forecasting model (WRF) was developed and tested for regional simulation and forecasting of weather. However, as regional climate modeling becomes more prevalent, use of the WRF for dynamic downscaling is also growing. Current published studies that utilize WRF in this manner include Leung and Qian (2009), Liang et al. (2005), and Lo et al. (2008). Despite this, little has been reported, to the authors' knowledge, on testing longer-term (e.g., seasonal) simulations from the WRF. Typically, most sensitivity studies using the WRF focus on single to multiple events, as in Gallus and Bresch (2006) where 15 cases are utilized. However, some responses of the model to specific setup options may not be apparent in shorter simulations and may only become evident over longer periods.

As part of a larger, global climate model downscaling project, numerous warm-season runs of the WRF have

Corresponding author address: Melissa S. Bukovsky, School of Meteorology, University of Oklahoma, 120 David L. Boren Blvd., Norman, OK 73072.

E-mail: bukovsky@ucar.edu been made with an assortment of options in search of a setup that would give reasonable results in a feasible amount of computational time. Parameterization, dynamics, domain, boundary, and nesting options have been explored along the way, and a switch from version 2.2 to version 3.0.1 of the WRF was also made. The goal of this note is to document the more interesting and, in some cases, unanticipated parts of this journey. Though it is not comprehensive enough to provide guidance regarding an optimal setup of the WRF, this brief study does call attention to certain problems that become prominent in the 4-month-long simulations presented. Obviously, it will cover some of the sensitivities found while using the WRF as a regional climate model and hopefully will be of use to others interested in using it as such. In addition, as some of the issues presented are not apparent in simulations on a day-to-day basis, it is hoped that this analysis will also be of interest to people who use the WRF in its more traditional roles in research and forecasting, whether or not they have moved on to higher resolutions.

This note provides a subjective evaluation of varying WRF simulations and a discussion of their differences. In section 2, a brief description of the WRF and a few of its options is presented, and the impact of a select 
number of variations on precipitation in the WRF is shown in section 3 .

\section{The WRF model and its setup}

Two versions of the WRF are used in this note, version 2.2 and version 3.0.1. New versions of the WRF are released periodically, and although they may contain updates and fixes, many aspects of the modeling framework remain the same. Version 3 was released during the initial modeling stages of an ongoing project related to this sensitivity study; thus, a decision was made to test it as well. Because precipitation was found to be quite sensitive to the version of the WRF used, the results are included within this note.

Initially, runs were completed using a 30-km-resolution domain with 28 vertical levels. All of the simulations presented here, however, were produced with a $30-\mathrm{km}-$ horizontal resolution domain nested inside of a larger 90-km-resolution domain. Nesting was required to remove large-scale flow problems that were resulting from the placement of the eastern boundary through the general region of the Bermuda high. Instead of increasing the size of the $30-\mathrm{km}$ domain to move this boundary farther east and, therefore, significantly increasing the computational time, nesting was used. ${ }^{1}$ Feedback between the nest and its parent domain is either on or off, depending on the simulation.

Initial and boundary conditions for the simulations are derived from the first version of the National Centers for Environmental Prediction (NCEP)-National Center for Atmospheric Research (NCAR) global reanalysis (NNRP; Kalnay et al. 1996). The NNRP has a horizontal resolution of $2.5^{\circ}$ with 17 pressure levels (excluding the surface) and is available in 6-h increments. The WRF is initialized on 23 April for each year simulated and run through 31 August.

Numerous parameterization options were tested, but only select variations will be covered here. All simulations shown use the Community Atmosphere Model 3.0 (CAM) radiation package for longwave and shortwave radiation. The CAM is more expensive to use than other radiation options, but it was ultimately deemed more appropriate for the $30 / 90-\mathrm{km}$-resolution simulations since cloud cover is fractional and a grid cell is not just defined as having cloud cover or not (Kiehl et al. 1998; Collins 2001; Collins et al. 2002).

\footnotetext{
${ }^{1}$ It was also noted before the $90-\mathrm{km}$ parent domain was added that placement of the southern boundary impacted moisture flow into the Great Plains. This was greatly overshadowed by the eastern boundary problem, but was later mitigated by placing the southern parent domain boundary through the Caribbean Sea.
}

TABLE 1. Notation and WRF options used for each simulation shown. Note that Simulation ID corresponds to the panels in Figs. 1 and 2 .

\begin{tabular}{cccccc}
\hline \hline $\begin{array}{c}\text { Simulation } \\
\text { ID }\end{array}$ & $\begin{array}{c}\text { WRF } \\
\text { version }\end{array}$ & $\begin{array}{c}\text { 30-km SST } \\
\text { update }\end{array}$ & $\begin{array}{c}\text { Inner } \\
\text { nest } \\
\text { feedback }\end{array}$ & LSM & CPS \\
\hline B & 2.2 & Off & On & 5 layer & KF \\
C & 2.2 & Off & On & Noah & KF \\
D & 2.2 & Off & Off & Noah & KF \\
E & 3.0 .1 & On & Off & Noah & KF \\
F & 2.2 & On & Off & Noah & KF \\
G & 3.0 .1 & On & On & Noah & KF \\
H & 3.0 .1 & On & Off & Noah & BMJ \\
\hline
\end{tabular}

Surface layer processes are handled by the MoninObukhov scheme in all simulations, and all but one employs the Noah land surface model (LSM; Ek et al. 2003). The other uses a less complex 5-layer diffusion model (Wang et al. 2007). Furthermore, all simulations employ the Yonsei University (YSU) planetary boundary layer (PBL) scheme (Hong et al. 2006).

The WRF Single-Moment 5-class microphysics parameterization is used in all simulations (Hong et al. 2004). For the convective parameterization scheme (CPS), the Kain-Fritsch (KF; Kain and Fritsch 1992; Kain 2004) CPS is utilized in all but one simulation. The other uses the Betts-Miller-Janjic scheme (BMJ; Betts 1986; Janjic 1994).

Other variations that will be shown include changes in feedback between the parent domain and nest, and time-varying sea surface temperature (SST) modifications. Table 1 lists the notation used for each run in the following section, as well as any varying options.

\section{WRF simulation comparison and discussion}

Figures 1 and 2 show 1991 May-August (MJJA) average precipitation for simulations forced by the NNRP for the $90-\mathrm{km}$ parent domain and the $30-\mathrm{km}$ nest, respectively. The domains have not been clipped to remove the relaxation halo, as evident in the pattern of precipitation framing each map. Figures $1 \mathrm{a}$ and $2 \mathrm{a}$ display the average precipitation from the North American Regional Reanalysis (NARR) for the corresponding time period, regridded to match the given WRF domain resolution (Mesinger et al. 2006). NARR data have a 32-km horizontal resolution (close to the resolution of the inner nest), and the precipitation from this reanalysis over the continental United States is superior to that in many other widely used reanalyses (Bukovsky and Karoly 2007). It does have, however, some problems over oceans, islands, and at country boundaries. 


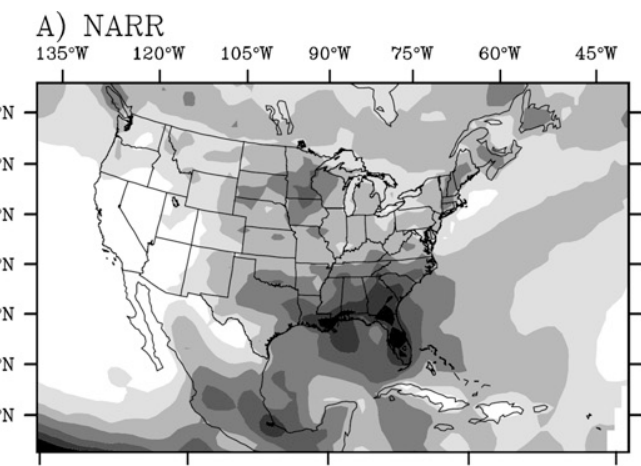

C)

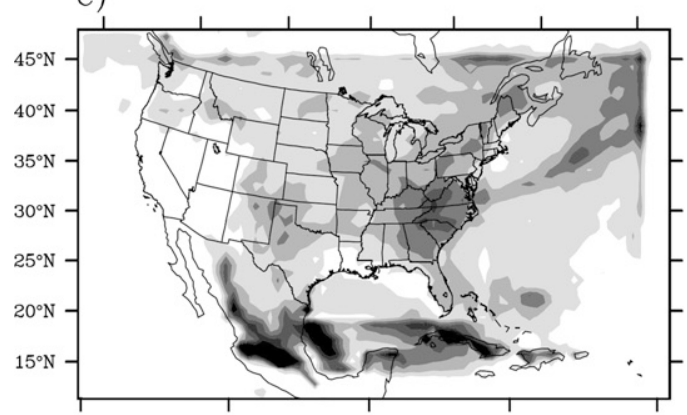

E)

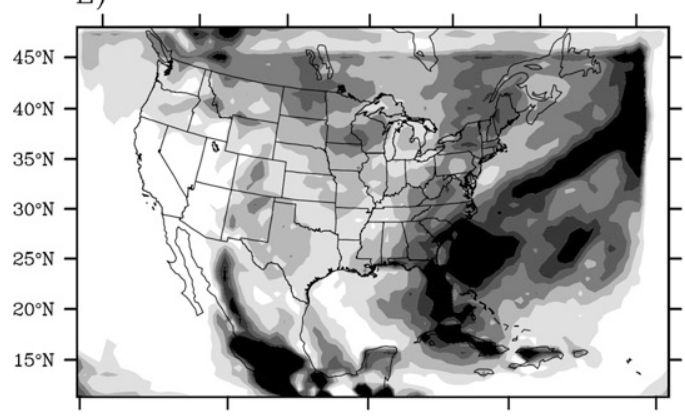

G)

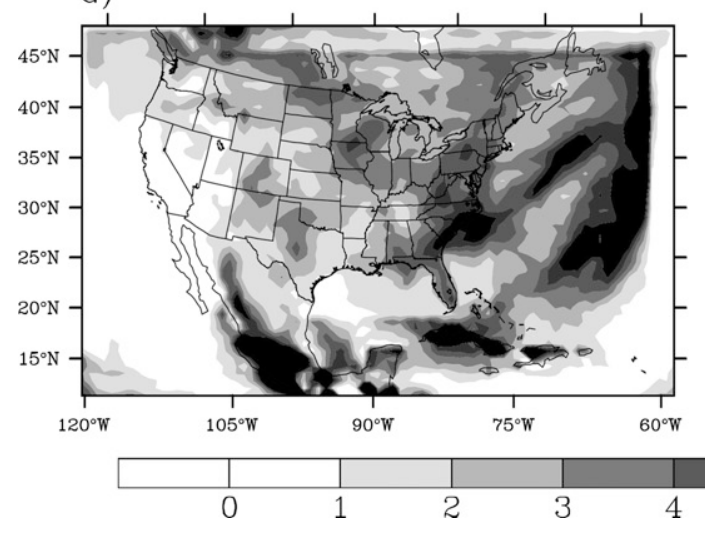

B)

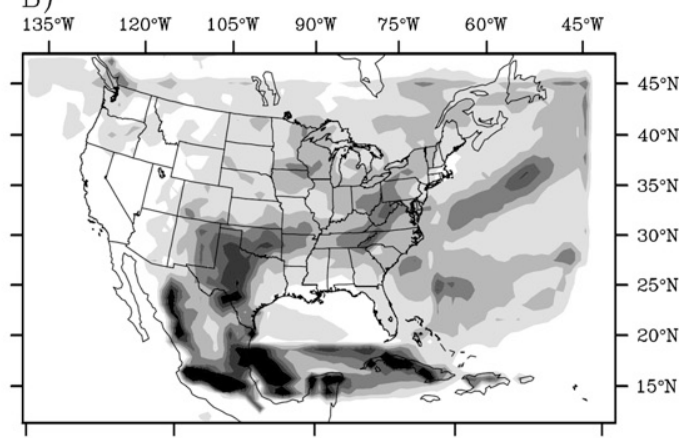

D)

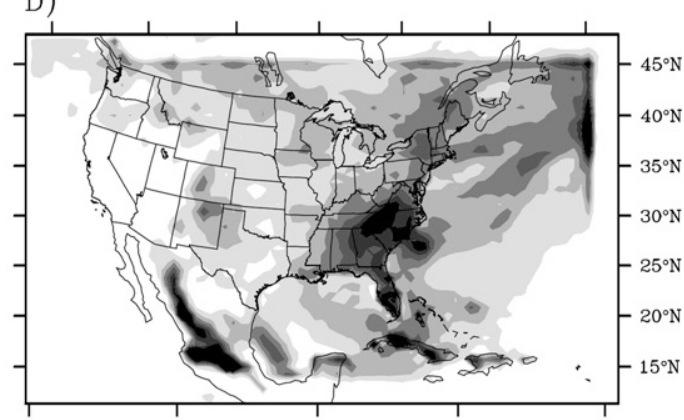

F)

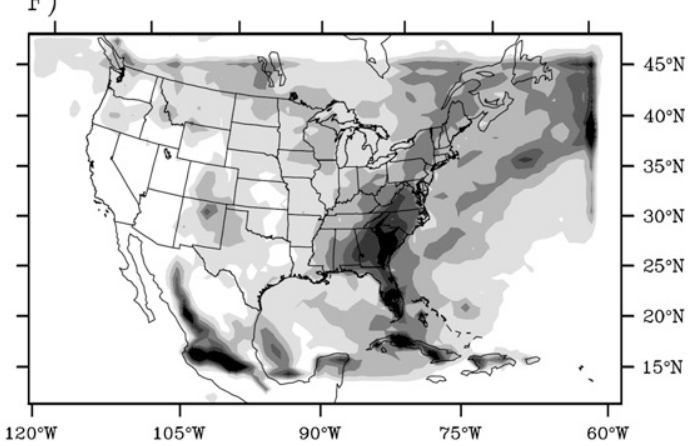

$\mathrm{H})$

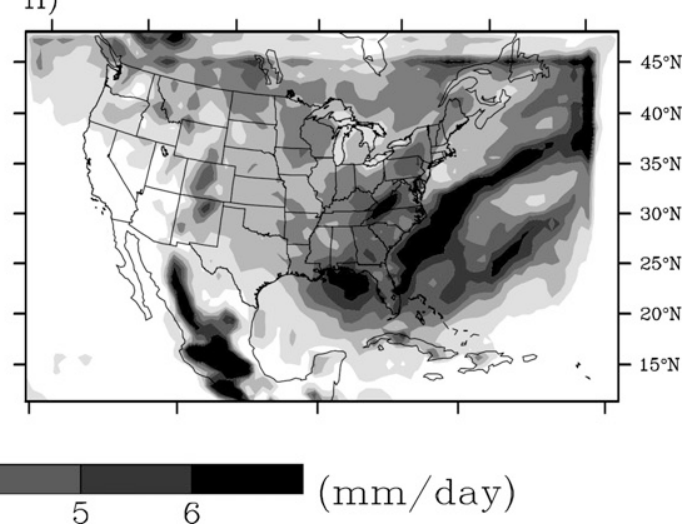

FIG. 1. 1991 MJJA average precipitation rate ( $\mathrm{mm} \mathrm{day}^{-1}$; contours) from (a) NARR and (b)-(h) 90-km WRF domain simulations. NARR data have been reprojected to match WRF domain size and resolution. Specification of the different WRF options in (b)-(h) is given in Table 1. 

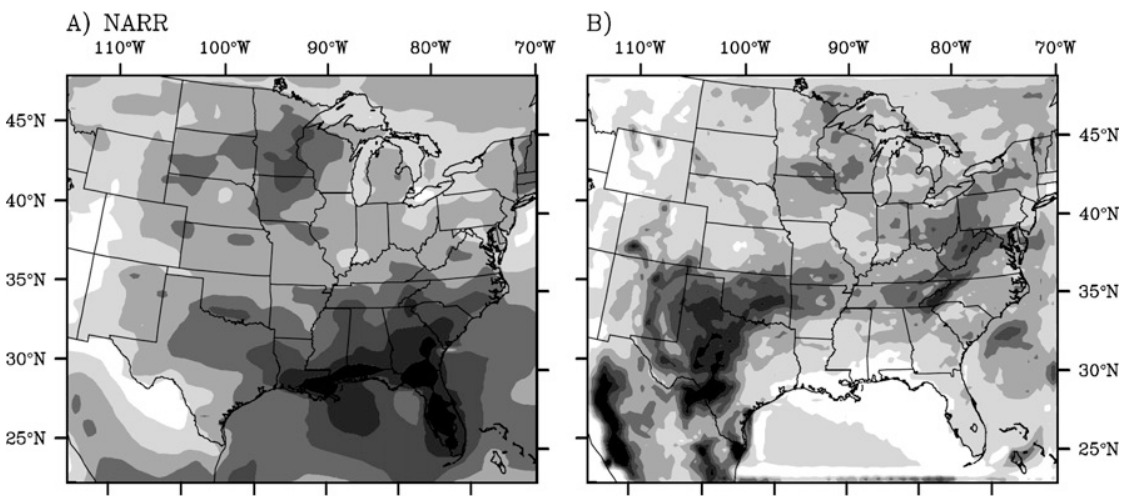

C)

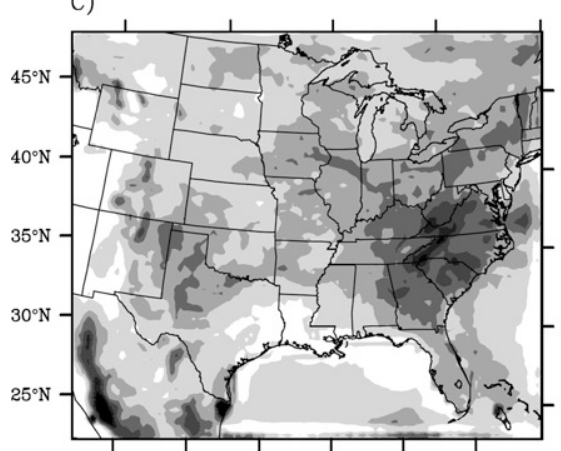

D)

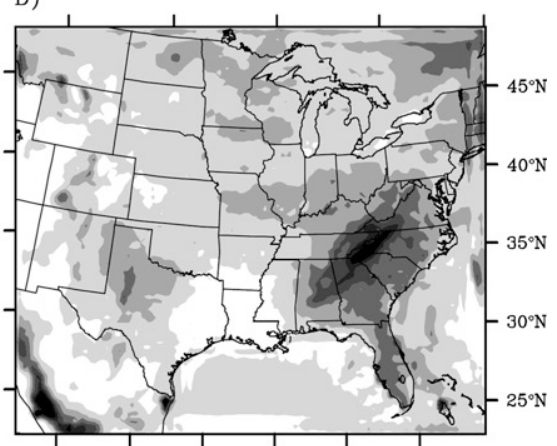

E)

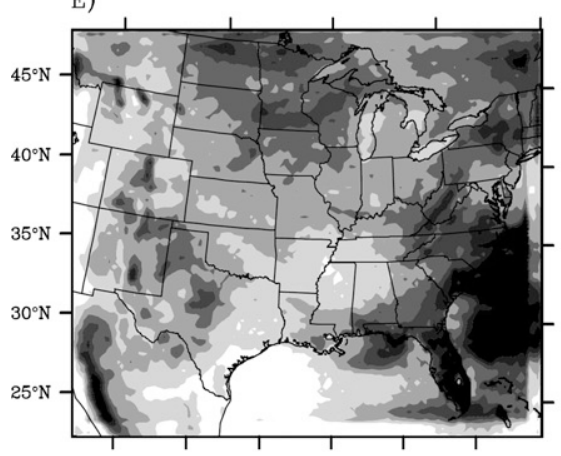

F)

G)
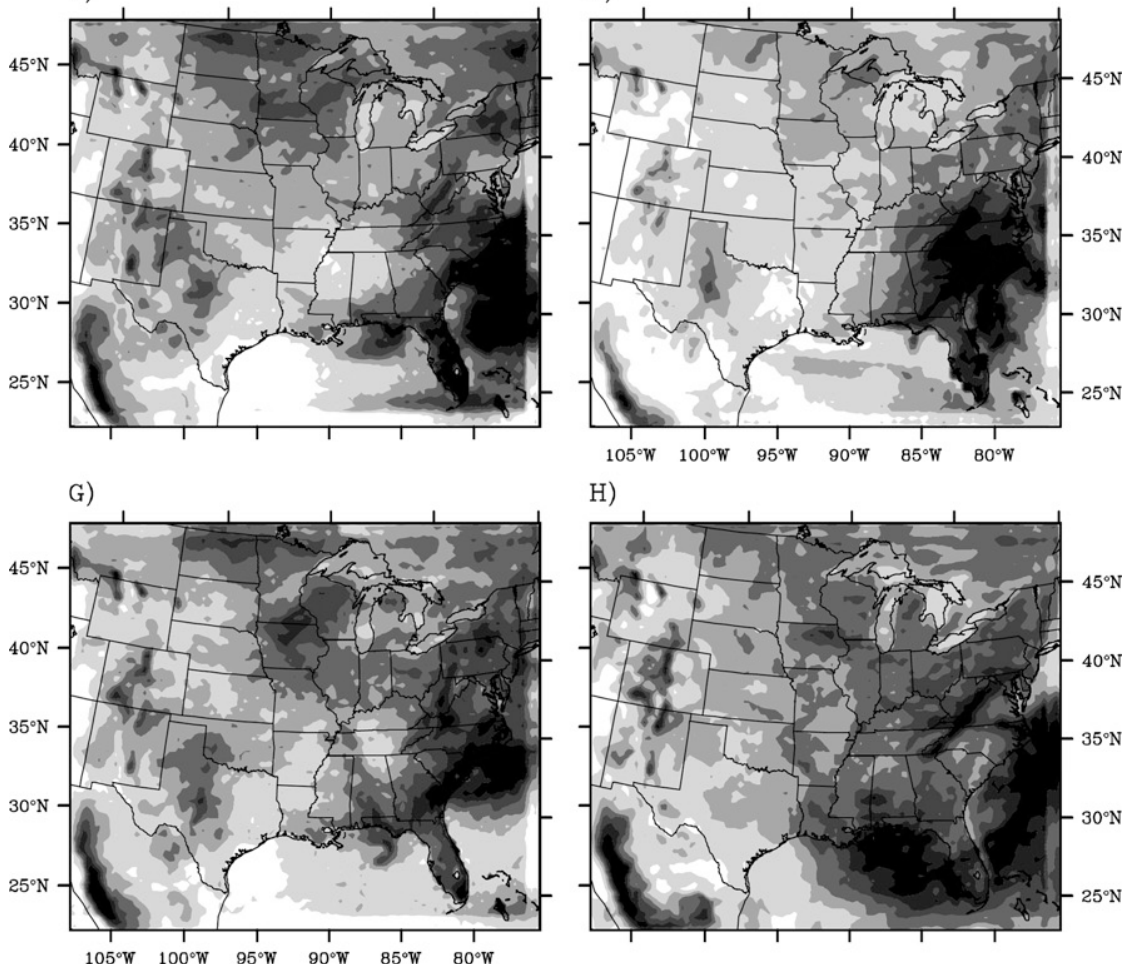

$\mathrm{H})$

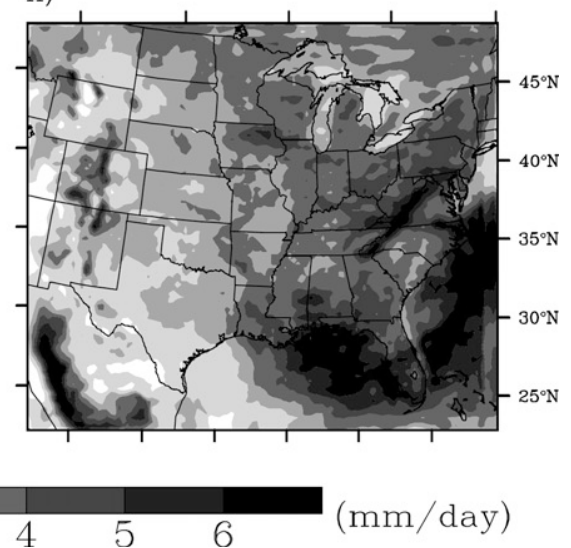

FIG. 2. As in Fig. 1, but for (b)-(h) 30-km inner WRF nest. NARR data have been reprojected to match WRF inner nest size and resolution. 
The pattern of average precipitation exhibited in Figs. 1 and 2 is moderately variable. Simulation B (Figs. 1b and $2 b),{ }^{2}$ unlike the others, uses the 5-layer LSM. It is identical to simulation $\mathrm{C}$ in every other aspect of its configuration. Changing from the simple LSM in simulation B to the more complex Noah LSM had an obvious impact on the amount of precipitation in Texas and Oklahoma and along the East Coast, especially east of the Appalachian Mountains. The 5-layer diffusion scheme and the Noah LSM provide very different fields of heat and moisture flux that must eventually account for the differences in precipitation. Unlike the Noah LSM, which predicts both soil temperature and moisture, the 5-layer LSM predicts only soil temperature and prescribes moisture availability given the land surface cover. ${ }^{3}$ This difference likely accounts for most of the variation seen between these two simulations. Latent heat (LH) flux from simulation B is approximately $10 \%-30 \%$ greater on average over the western Great Plains and more so over western Texas than in simulation $\mathrm{C}$, while the average $\mathrm{LH}$ flux over the eastern seaboard and Appalachian region is $20 \%-50 \%$ greater in simulation C than B. Differences in surface sensible heat (SH) flux are also evident and follow a similar pattern. That is, $\mathrm{SH}$ flux over the central United States is much greater in simulation B than in C (often $50 \%-100 \%$ greater), and is slightly lower in $\mathrm{B}$ than in $\mathrm{C}$ in some East Coast areas. The impacts of both can clearly be seen in average 2-m temperature and specific humidity fields (not shown).

The only other example of the impact of a physical parameterization change is conveyed in simulation $\mathrm{H}$. This simulation used the BMJ CPS instead of the KF. It is otherwise identical to the simulation shown in E. This change caused minor differences in average precipitation between simulations $\mathrm{H}$ and $\mathrm{E}$ in most regions of the domain, but a more obvious change in the character of precipitation over Florida. Instead of producing a relative maximum, there is a minimum of precipitation over Florida relative to the surrounding waters in simulation $\mathrm{H}$, using the BMJ CPS. Though average total precipitation is shown, the components of precipitation clearly indicate that this difference is rooted in convective precipitation and not large-scale precipitation. Neither simulation has difficulty with the diurnal

\footnotetext{
${ }^{2}$ Panel labels in Figs. 1 and 2 correspond to the simulation ID given in Table 1.

${ }^{3}$ It must be noted that the 5-layer LSM may not be appropriate for regional climate studies because it neglects a feedback that is important over long time scales. Using it over this moderateduration 4-month period produced enough of a difference to warrant inclusion in this note, however.
}

cycle of the land-sea breeze and resulting daytime convergence over the Florida Peninsula either. Thus, the exact reason for the discrepancies has yet to be identified. Feedbacks between the CPS and other physical processes combined with a relatively limited frequency of model output (currently $3 \mathrm{~h}$ ) and only 4 months of simulation make a diagnosis difficult. However, the 3-h evolution of vertical profiles of temperature and moisture taken over the Florida Peninsula and the surrounding waters provides some insight (not shown). In general, it appears that shallow convection is triggering more frequently in simulation $\mathrm{H}$ over Florida than over adjacent water, leaving characteristic footprints in profiles and a deeper, drier, more mixed PBL over land, as explained in Baldwin et al. (2002). There is a lesser impact on the PBL over water due to shallow convection, and the BMJ scheme seems to transition to deep convection more frequently over water than over nearby land, both possibly due in part to greater available lowlevel moisture. Simulation $\mathrm{E}$ is more difficult to decipher since convection in the KF scheme does not leave as distinctive a mark on vertical profiles. However, for an unidentified reason, there is less mid- to upper-level moisture over the Gulf of Mexico than there is over Florida. Though there is more low-level moisture, this, combined with an existing warm layer above the PBL, would certainly act to inhibit convection.

There are also several discrepancies apparent in Figs. 1 and 2 that are not rooted in model physical parameterizations, but are potentially more important to call attention to. For example, the simulations shown in B, C, and $\mathrm{G}$ all exhibit a very distinct edge in the pattern of precipitation in the Gulf of Mexico and off the East Coast, which marks the location of the inner nest. These particular simulations all used two-way feedback (i.e., the feedback from the nest to the parent domain was turned on). Similar discontinuities are also obvious in the specific humidity fields in these simulations at levels below the tropopause (not shown). This problem is evident in WRF versions 2.2 and 3.0.1 (simulations $B$ and $C$ versus $G$, respectively). However, turning the feedback off had a much greater impact in version 2.2 than in version 3.0.1. Both versions, when feedback is turned off, exhibit an increase in precipitation over the Southeast, especially over Florida. Simulations $G$ and E illustrate the impacts of this change on otherwise identical setups of WRF version 3.0.1 (no equivalent illustration with version 2.2 shown). This problem is not evident while examining the 3-hourly precipitation output, as it is only upon averaging over a longer period that it becomes evident.

It was not noticed through many runs that SST was not updating in the inner nest in WRF version 2.2, although the SST in the parent domain was updating properly. 

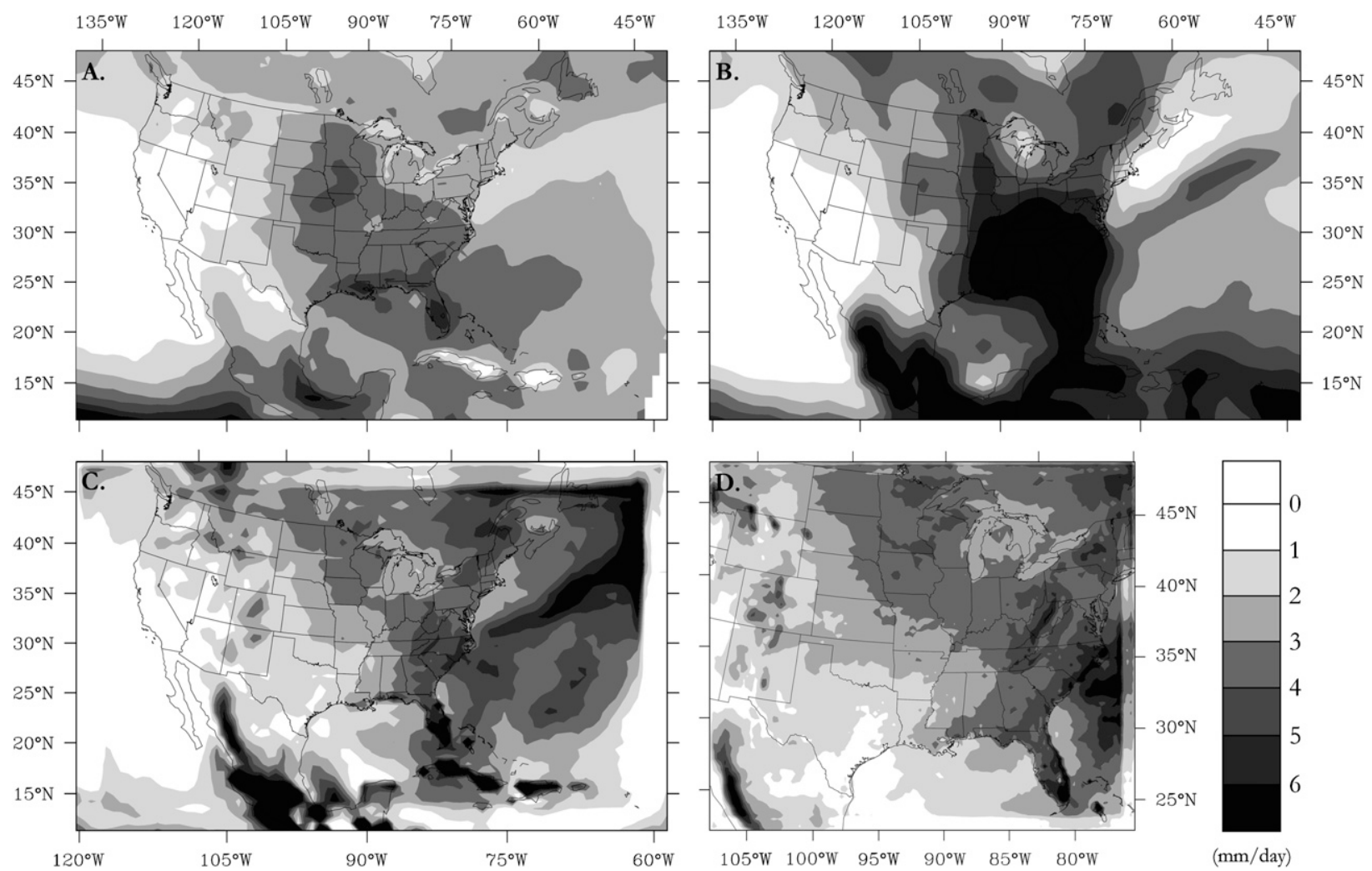

FIG. 3. The 1991-95 MJJA average precipitation rate (mm day ${ }^{-1}$; contours) from (a) NARR, (b) NNRP, (c) WRF 90-km parent domain, and (d) WRF 30-km inner nest. NARR data have been reprojected to match 90-km WRF parent domain size and resolution.

The fix for this required a slight change in the WRF initialization program code for real data cases, and it is not a problem in version 3.0.1. The sensitivity of precipitation to time-varying SSTs in the inner nest can clearly be seen by comparing Figs. $2 \mathrm{~d}$ and $2 \mathrm{f}$. Fixing the SST error in the nest increases the average precipitation in the Southeast as well as in the secondary maximum in the Great Plains and north-central United States, possibly because of greater moisture flux, as the SSTs are then warmer as the season evolves. Though this error is also present in simulations $\mathrm{B}$ and $\mathrm{C}$, the simulations depicting the impact that LSM choice has on warmseason precipitation for this year, it is consistent between the two. Thus, differences would likely be present even if the SST error were not.

Certain panels in Figs. 1 and 2 also illustrate the effect that switching WRF versions had on average precipitation. The best example of this impact can be seen by comparing simulations E and F. Both have SST updating in the inner nest and feedback off-they are, subjectively speaking, the best and most problem-free simulations produced for this particular season from each version of the WRF. Except for the model version, the setups are identical. Average precipitation in the parent domain is noticeably higher in the version 3.0.1 simulation than version 2.2 (domain average of 2.62 versus $1.47 \mathrm{~mm} \mathrm{day}^{-1}$, respectively). The same effect materializes in the $30-\mathrm{km}$ nest, although not to the same extent (nest average of 2.85 versus $2.25 \mathrm{~mm} \mathrm{day}^{-1}$, respectively). Average precipitation in the version 3.0.1 simulation (E) is favorably higher in the Great Plains and north-central United States. The exact cause of these differences is unknown and outside the scope of this note. Only one parameterization used between these runs had any significant changes made to it for version 3 (the YSU PBL scheme, to improve the stable PBL), and no bug fixes apply to the currently utilized options. It may be that changes made outside of the model physics are having the greatest impact.

In the end, the WRF setup used in simulation $\mathrm{E}$ was chosen for continued study. As mentioned above, it is one of the best and most problem-free configurations tested, subjectively speaking, including those not shown here. Thus far, all of the simulations have been assessed over one 4-month period in 1991. Simulation E, however, has been run for five consecutive warm seasons. The average precipitation for this simulation of MJJA of 1991-95 is shown in Fig. 3. For comparison, average precipitation 
from the NARR and the NNRP for the corresponding period is also shown. While not without problems, the dynamically downscaled NNRP/WRF simulations for this longer period are acceptable. Overall, the 5-yr nested WRF precipitation agrees better with the NARR than the NNRP precipitation. Average precipitation in the central United States and the Southeast may be too light, but in contrast to the plethora of precipitation over the Southeast in the NNRP, for example, the nested WRF simulations are a definite improvement.

\section{Final comments}

Precipitation produced in varying WRF simulations has been presented in this note. Running WRF forced by the NNRP as a nested regional climate model has brought to light some issues that may not otherwise be as apparent in shorter-term weather forecast model runs. Specifically, there is a clear issue with feedback between the inner nest and parent domain that greatly impacts average precipitation when turned on-this is present in both WRF versions examined. Two-way nesting may not have a negative impact that is as visible as the one shown here in other applications, but in certain situations, it undoubtedly is not the best option. Likewise, two-way nesting may have an unknown impact on shorter simulations that may not be as easily diagnosed, but would likely be undesirable.

An easily made error regarding SSTs in version 2.2 was also discovered, and a change in LSM was found to have a clear impact on the spatial distribution of precipitation. Given that there are two different types of LSMs utilized in this study, it must be emphasized that an LSM that predicts soil moisture is preferred over one that does not in regional climate studies because an important feedback over long time scales is otherwise neglected.

Furthermore, while changing physical parameterizations, especially the convective parameterization, was expected to have an influence on average precipitation, it was not anticipated that switching WRF versions would have as great an impact on average precipitation as it did. Despite the variety of issues discussed, a reasonable setup of the WRF was found that produced simulations that improved upon the precipitation fields from the NNRP, the source of initial and boundary conditions for these simulations.

The goal of this note is to inform WRF users of some of the potential effects that varying the model setup can have on precipitation when averaged over longer periods, as some phenomena may not be apparent on a day-to-day basis. It also serves as a reminder that, in any manner of usage, blind application of the WRF is cer- tainly not recommended. Similarly, this note serves as a warning to others looking to use the WRF as a nested regional climate model. Care must be taken and simulations should be examined thoroughly.

Acknowledgments. The authors thank the three anonymous reviewers of this manuscript for their comments and suggestions. Support for this project has been provided by the Gary Comer Science and Education Foundation. David Karoly is the recipient of an Australian Research Council Federation Fellowship (Project Number FF0668679). NARR data were obtained from the NCEP Web site (http://wwwt.emc.ncep.noaa.gov/mmb/ rreanl/). NNRP data were obtained from the NCAR Computational and Information Systems Laboratory Research Data Archive (http://dss.ucar.edu/datasets/ ds090.0/).

\section{REFERENCES}

Baldwin, M. E., J. S. Kain, and M. P. Kay, 2002: Properties of the convection scheme in NCEP's Eta model that affect forecast sounding interpretation. Wea. Forecasting, 17, 1063-1079.

Betts, A. K., 1986: A new convective adjustment scheme. Part I: Observational and theoretical basis. Quart. J. Roy. Meteor. Soc., 112, 667-691.

Bukovsky, M. S., and D. J. Karoly, 2007: A brief evaluation of precipitation from the North American Regional Reanalysis. J. Hydrometeor., 8, 837-846.

Collins, W. D., 2001: Parameterization of generalized cloud overlap for radiative calculations in general circulation models. J. Atmos. Sci., 58, 3224-3242.

_ J. K. Hackney, and D. P. Edwards, 2002: An updated parameterization for infrared emission and absorption by water vapor in the National Center for Atmospheric Research Community Atmosphere Model. J. Geophys. Res., 107, 4664, doi:10.1029/2001JD001365.

Ek, M. B., K. E. Mitchell, Y. Lin, P. Grunmann, E. Rodgers, G. Gayno, and V. Koren, 2003: Implementation of the upgraded Noah land-surface model in the NCEP operational mesoscale Eta model. J. Geophys. Res., 108, 8851, doi:10.1029/ 2002JD003296.

Gallus, W. A., Jr., and J. F. Bresch, 2006: Comparison of impacts of WRF dynamic core, physics package, and initial conditions on warm season rainfall forecasts. Mon. Wea. Rev., 134, 26322641.

Hong, S. Y., J. Dudhia, and S. H. Chen, 2004: A revised approach to ice microphysical processes for the bulk parameterization of clouds and precipitation. Mon. Wea. Rev., 132, 103-120.

— , Y. Noh, and J. Dudhia, 2006: A new vertical diffusion package with an explicit treatment of entrainment processes. Mon. Wea. Rev., 134, 2318-2341.

Janjic, Z. I., 1994: The step-mountain Eta coordinate model: Further developments of the convection, viscous sublayer, and turbulence closure schemes. Mon. Wea. Rev., 122, 927-945.

Kain, J. S., 2004: The Kain-Fritsch convective parameterization: An update. J. Appl. Meteor., 43, 170-181.

— function" in numerical forecasts of mesoscale convective systems. Meteor. Atmos. Phys., 49, 93-106. 
Kalnay, E., and Coauthors, 1996: The NCEP/NCAR 40-Year Reanalysis Project. Bull. Amer. Meteor. Soc., 77, 437-471.

Kiehl, J. T., J. J. Hack, G. B. Bonan, B. A. Boville, D. L. Williamson, and P. J. Rasch, 1998: The National Center for Atmospheric Research Community Climate Model: CCM3. J. Climate, 11, 1131-1149.

Leung, L. R., and Y. Qian, 2009: Atmospheric rivers induced heavy precipitation and flooding in the western U.S. simulated by the WRF regional climate model. Geophys. Res. Lett., 36, L03820, doi:10.1029/2008GL036445.

Liang, X. Z., H. I. Choi, K. E. Kunkel, Y. Dai, E. Joseph, and J. X. L. Wang, 2005: Surface boundary conditions for meso- scale regional climate models. Earth Interactions, 9. [Available online at http://EarthInteractions.org.]

Lo, J. C. F., Z. L. Yang, and R. A. Pielke Sr., 2008: Assessment of three dynamical climate downscaling methods using the Weather Research and Forecasting (WRF) model. J. Geophys. Res., 113, D09112, doi:10.1029/2007JD009216.

Mesinger, F., and Coauthors, 2006: North American Regional Reanalysis. Bull. Amer. Meteor. Soc., 87, 343-360.

Wang, W., D. Barker, J. Bray, C. Bruyère, M. Duda, J. Dudhia, D. Gill, and J. Michalakes, cited 2007: ARW Version 2 Modeling System User's Guide. [Available online at http://www.mmm. ucar.edu/wrf/users/docs/user_guide/ARWUsersGuide.pdf.] 


\section{University Library}

\section{- M M I N E R VA A gateway to Melbourne's research publications}

Minerva Access is the Institutional Repository of The University of Melbourne

Author/s:

Bukovsky, MS;Karoly, DJ

Title:

Precipitation Simulations Using WRF as a Nested Regional Climate Model

Date:

2009-10-01

Citation:

Bukovsky, M. S. \& Karoly, D. J. (2009). Precipitation Simulations Using WRF as a Nested

Regional Climate Model. JOURNAL OF APPLIED METEOROLOGY AND CLIMATOLOGY, 48 (10), pp.2152-2159. https://doi.org/10.1175/2009JAMC2186.1.

Publication Status:

Published

Persistent Link:

http://hdl.handle.net/11343/32786 